\title{
EN LOS DOSCIENTOS AÑOS DE LA MUERTE DE KANT
}

Por:

Wisberto Navarro Salcedo

Magister en Filosofia

Docente departamento de Psicopedagogía

Facultad de Educación

Universidad Surcolombiana

\section{RESUMEN}

En este articulo se destaca el papel de Kant en la epistemología, en que consiste su revolución filosófica y como se compara con la transformación que hizo la ciencia empírico-analítca en el saber, tanto en sus métodos como en sus fines.

Se analizan las propuestas del empirismo y el racionalismo y se contrastan con la Kantiana. Finalmente se expone en que se fundamenta la originalidad de Kant en las teoría del conocimiento

\section{PALABRAS CLAVES}

Ciencia, conocimiento, empirismo, epistemología, experimento, racionalismo.

\section{INTRODUCCIÓN}

Escribir sobre Kant es rendirle homenaje a una de las filosofías más importantes de la modernidad. Aunque Konisberg (hoy Kaliningrado), el lugar de su nacimiento, parezca tan lejano como su muerte el 12 de febrero de 1804 , su vasta obra constituye un punto de inevitable referencia para cualquier planteamiento posterior, y a la vez, un tema de constante reflexión para todas las escuelas y tendencias, incluidas aquellas que como la filosofía analítica o el neomarxismo- mas alejadas pudieran estar de sus supuestos.

Este filosofo alemán, uno de los que ha tenido mayor influencia en occidente, dio un giro de $180^{\circ}$ a la historia del pensamiento, con su famosa revolución copernicana en el conocimiento. Su revolución es una metáfora con la cual se alude al cambio radical de perspectiva que plantea. 


\section{LA REVOLUCIÓN COPERNICANA EN EL CONOCIMIENTO}

El giro copernicano de Kant consiste, en pensar que la filosofía para entrar en el camino seguro en el conocimiento, debe hacer lo mismo que hizo Copernico en astronomía: si éste, para explicar los movimientos celestes, entendió que era mejor partir del supuesto de que era el espectador quien giraba, de manera parecida Kant cree que sólo podemos tener un verdadero conocimiento de las cosas -un conocimiento universal y necesario- si el objeto depende del pensamiento, para ser conocido, y no a la inversa. Éste es el supuesto de que parte la filosofía trascendental de Kant. Si bien es cierto que esta revolución ha identificado el aporte de Kant a la historia del pensamiento, en el fondo utilizó para la filosofía, no solo la idea de Copernico, sino el nuevo método para el conocimiento de la realidad, sus palabras al respecto son elocuentes:

«Cuando Galileo hizo rodar sobre un plano inclinado las bolas cuyo peso había señalado, o cuando Torricelli hizo que el aire soportara un peso que el sabía igual a una columna de agua que le era conocida, o cuando mas tarde Sthal transformo metales en cales $y$ estas en metal, quitándole o volviéndole a poner algo, puede decirse que para los físicos apareció un nuevo día. Se comprendió que la razón solo descubre lo que ella ha producido según sus propios planes; que debe marchar por delante con los principios de sus juicios determinados según leyes constantes, y obligar a la naturaleza a que responda a lo que la propone, en vez de ser esta ultima quien la dirige y maneje. De otro modo no seria posible coordinar en una ley necesaria observaciones accidentales que al azar se han hecho sin plan ni dirección, cuando precisamente es lo que la razón busca y necesita. ..... De suerte que si bien se advierte debe la física toda la provechosa revolución de sus pensamientos a la ocurrencia de que solo debe buscar en la naturaleza (no inventar) aquello que la razón misma puso en conformidad con lo que desea saber, y que por si solo no seria factible alcanzar. A esta revolución debe principalmente la física haber entrado en el seguro camino de la ciencia, después de haber sido por largos siglos un simple ensayo $y$ tanteo» ${ }^{1}$

Se puede anotar que Kant, en ningún momento se refiere explícitamente a la revolución copernicana ni relaciona con ella su cambio de orientación filosófica, pero que sí habla del cambio que en metafísica(filosofía) debe ser como el de Galileo, y relaciona el «cambio de método» en filosofía con los de la matemática y la ciencia natural, las cuales se han convertido en lo que son gracias a una revolución repentinamente producida.

Kant fundó una filosofía nueva que en sus puntos fundamentales nada tiene en común con alguna de las anteriores: Antes de Kant la filosofía, en todas la escuelas, quería ser una explicación de las cosas; todas se esforzaban a su manera en ser un sistema universal y trazaban un cuadro mas o menos completo que comprendía y abarcaba todas las cosas y toda la realidad.

La filosofía tenia así un dominio fácil, e imperaba en un ancho territorio cuyas provincias estaban sin dueño, sin embargo cuando aparecen las ciencias particulares 
estas provincias se fueron poblando $y$ reclamaron su autonomía. En este momento es cuando empiezan las ciencias particulares a tener, en cierto sentido, una doble existencia: había una física racional y otra empírica, una psicología racional y otra empírica así con las demás ciencias incipientes

Al lado de la filosofía de la naturaleza, procedente de la metafísica, se presento la física, independiente de toda base filosófica, y fundada en la sola observación. Esta aparición ocasionó un conflicto, en cuanto terminaron disputándose el estudio de un mismo objeto.

Los físicos se preguntan sobre la pretensión de la llamada filosofía de la naturaleza que especulaba sobre cosas que fundamentalmente ellos investigaban: los hechos de la naturaleza y que según ellos solo pueden ser conocidas por medio de una observación precisa y exacta, y concluian: o sobraba la física o sobraba la filosofía de la naturaleza.

Además la filosofía de la naturaleza contradecía las afirmaciones de la física y establecía una serie de afirmaciones sin fundamento sobre los objetos que la física estudiaba. Por ejemplo Galileo afirmaba que todos los cuerpos (en caída libre y a la misma altura), caían al mismo tiempo a la tierra, mientras que

Aristóteles,(pilar de la metafísica), afirmaba que los cuerpos mas pesados caían primero.
Con semejantes objeciones se rebelaron la demás ciencias contra la filosofía, y con tanto más éxito, cuanto mas iban fortaleciéndose, por el valor de sus trabajos y los resultados que alcanzaban. La filosofía pudo sortear el temporal por su prestigio en la antigüedad y el poder dado a la teología en la edad media, pero desde la reforma protestante y los grandes descubrimientos que la precedieron, progresaron tantos las ciencias particulares, que no quedo otro camino a la filosofía que, o bien fundirse con ellas, o doblegarse a las necesidades de su tiempo. Por esto la relación que existe entre experiencia y teoría establece la posición y las tendencias de los nuevos sistemas filosóficos.

\section{LAS SOLUCIONES DE BACON Y DESCARTES}

Bacon planteó que había llegado el tiempo de una nueva ciencia: la física la cual se fundamentaba en un nuevo método de conocimiento que privilegiaba la observación y la inducción. Hizo depender de ella la filosofía, a la que convirtió en propedéutica y órgano de las ciencias particulares, que examinan la naturaleza de los objetos. Así la filosofía pasó al campo de las ciencias exactas, siendo su método. La nueva tarea encomendada era dar 
las pruebas, repetir y demostrar que el ser humano no tenía otro instrumento que el que necesitaban las ciencias experimentales.

Los contradictores del empirismo baconiano, que en la filosofía moderna parten del racionalismo cartesiano, y después de Leibniz, indagan el conocimiento de los objetos por medio del entendimiento puro, $y$ construyen con este procedimiento sus conceptos sobre la realidad. Método que es de naturaleza muy diferente a los de las ciencias experimentales.

La oposición entre racionalismo o empirismo se expresa fundamentalmente por la pugna que se estableció entre el método racional que parte de ciertos principios, y el empírico que solo pretende la explicación exacta de las cosas. Los razonamientos que construye el entendimiento puro, sobre la naturaleza de las cosas deben tener su prueba definitiva en la existencia misma de los hechos, mientras no se obtiene esta prueba, la metafísica tiene una debilidad y la cuestión se pone, desde luego, a favor de la observación empírica.

Esta debilidad se halla en el mismo Descartes, cuya filosofía no resiste las pruebas de los hechos demostrados porque contradecía las leyes que habían demostrado Copernico y Galileo por la forma como Descartes entendía su filosofía, la esencia de la naturaleza y de la materia, su paradigma no podía aceptar nunca el movimiento de los cuerpos y la ley de la caída de los cuerpos de Galileo. El racionalismo se halló así por sus conceptos no solo inferior a los hechos evidentes de la naturaleza, sino en oposición a ellos.
El racionalismo quería pensar de una manera puramente matemática, como si el entendimiento puro y como si las cosas en el mundo no fueran mas que cantidades abstractas. Para esta escuela, filosofar era pensar con orden matemático, pues planteaba que toda demostración debía darse bajo la forma evidente de una igualdad $A=A ; y$ que ninguna verdad valiera como tal sino estaba constituida como $2+2=4$, y en general no tener por cierto y evidente sino los principios demostrados de una manera matemática.

La filosofía de Spinoza llevo hasta las últimas consecuencias el método cartesiano. Spinoza explicó por las reglas matemáticas, no solo la naturaleza., sino también la vida humana y las pasiones. Fundó una teología geométrica, una moral geométrica. Su doctrina filosófica comparada con la vida y sus manifestaciones, parecía inmutable e inmóvil como un cuerpo matemático. Los hechos de la experiencia no tienen para Spinoza valor alguno, y es su filosofía un instrumento completamente inútil para la experiencia: están las dos mirando respectivamente a puntos opuestos, como si nada tuvieran de común entre si.

Leibniz intento sacar a la filosofía de esta situación y trato de ser el mediador entre la filosofía y la experiencia. Libre por completo de todo dogmatismo, sentía una adhesión tan grande por la filosofía como por las ciencias experimentales y puso a ambas en armonía.

En matemáticas descubrió el calculo diferencial e infinitesimal, (existe una polémica con Newton sobre el tema), y halla su correspondencia en la filosofía, en la ley 
de continuidad $y$ en las diferencias infinitamente pequeñas, que constituyen el paso gradual de unas cosas a otras. La oposición entre lo orgánico y lo inorgánico, lo físico y lo espiritual, lo mecánico y lo moral fue resuelta con el concepto de continuidad en el mundo gradual y uniforme de las fuerzas vivas $y$ activas.

Wolf y sus discípulos se presentan como los sucesores de Leibniz y terminan separando lo que en las dos ciencias había unido este. Tomaron la filosofía leibniziana y con el auxilio de la matemática, le dieron una estructura de sistema, de tal manera que terminaron volviéndola escolástica.

La escuela Leibniz-wolfiana dominó todas las universidades alemanas en el siglo XVIII. Su esfera de acción fueron las cátedras y sus representantes los profesores. Su importancia consiste en que al separar la filosofía de las ciencias experimentales $y$ al ponerlas una frente a otra, hizo evidente la delación que entre ambas existía y mas fácil su comparación. Kant realizó mas tarde esta comparación, lo cual muestra la influencia que ejercieron los Wolfianos, a cuya escuela había pertenecido, y la transición entre Leibniz y aquel.

\section{RELACIONES ENTRE KANT Y LAS FILOSOFIAS ANTERIORES}

En el pensamiento de Kant pueden encontrarse, como se vera mas adelante, la influencia de gran parte de las filosofías anteriores, no solo alemanas sino también inglesas y francesas. Por este motivo suele presentársele como la sintesis entre el racionalismo y el empirismo que habían dominado la filosofía europea en los siglos
VXII y XVIII. Esta presentación esquemática, es sin duda útil desde el punto de vista didáctico pero se presta a malos entendidos. Y el más grave de ellos a considerar el empirismo y el racionalismo como dos corrientes aisladas una de la otra que se desarrollan en completa independencia, durante casi dos siglos, y que confluyen por primera vez en Kant.

Pero esto no es así, es mejor hablar de filosofías orientadas unas al método de los matemáticos, (como el cartesianismo), y otras al método de los físicos, (como el empirismo ingles). Por lo tanto ambas son racionalistas (en la medida que utilizan una lógica), al igual que lo son las filosofías, (por ejemplo las de Berkeley y la de Hume), dirigidas a demostrar la insuficiente racionalidad de la matemática y de la física.

La anteriores filosofías ejercerán una profunda influencia en Kant, y determinan en el la plena necesidad de armonizar el razonamiento de tipo matemático con el de tipo experimental. Desde esta perspectiva se puede afirmar que el pensamiento de Kant se vuelve a vincular directamente con el de Galileo, que en el comienzo de la modernidad proclamo el acuerdo entre matemática y experimento, condición indispensable para el progreso de la ciencia. Galileo trato de demostrar un método que evidenciará tal acuerdo; pero dejo a la posteridad la difícil tarea de justificarla en el plano filosófico Esta justificación es el centro de la problemática kantiana.

La filosofía que encontró Kant había tomado dos posiciones: en la primera abandonó su lugar y se paso a las ciencias experimentales y en la segunda permaneció en oposición a 


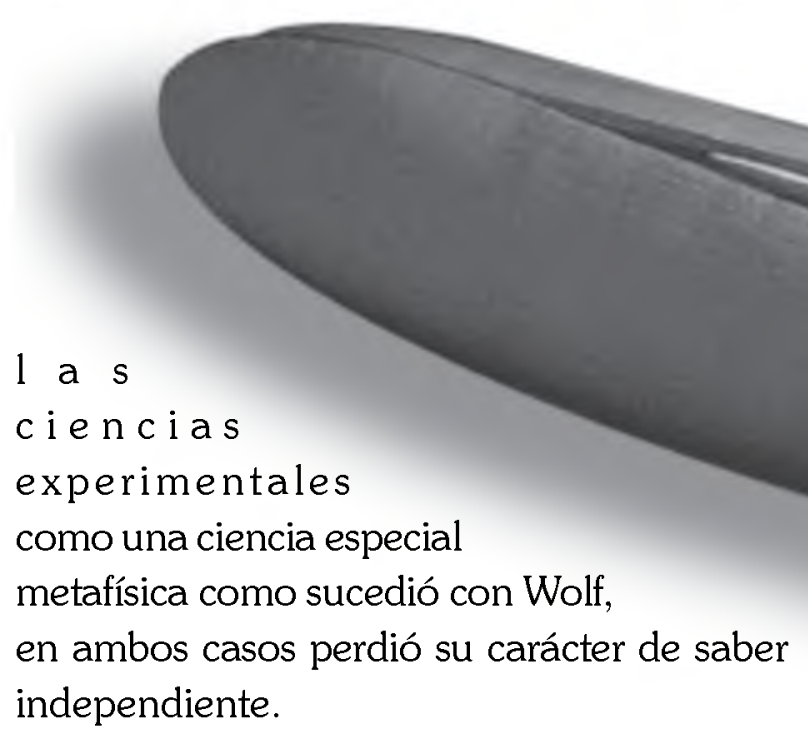

La filosofía recobra su carácter independiente, según Kant, cuando su objeto sea tan firme como los son los de las ciencias experimentales. Solo cuando encuentre un objeto de estudio que las demás ciencias no puedan investigar, y que a la vez no sea menos evidente que cualquier otro objeto de las demás ciencias.

La pregunta es la siguiente: ¿existe un objeto, que reconocido efectivo por las demás ciencias, no sea, sin embargo, estudiado por ninguna de ellas? Kant afirma que si existe $y$ es el hecho mismo de la explicación científica, pues las matemáticas, la física y la experiencia no se explican a si mismas.

Esta ciencia nueva y necesaria es la filosofía, la lucha entre esta y la ciencias desaparece de este modo. Porque lucha solo puede durar el tiempo en que unas y otras discutan el objeto que investigan, y al desaparecer la causa desaparece la disputa.

Desde la perspectiva Kantiana se investigan distintos campos: el objeto de la experiencia son las cosas, los fenómenos de la naturaleza, y el objeto de la filosofía es la experiencia y en general el mismo hecho del conocimiento humano. Deja, aquí, la filosofía de ser una explicación de las cosas para ser una explicación del conocimiento de las cosas, se convierte en Gnoseología o, con más precisión, en epistemología.

Este punto de vista tan fundamental para la filosofía moderna, fue descubierto por Kant, pues para éste el método experimental o científico era incuestionable. La nueva empresa que Kant realizó con éxito en el campo de la filosofía consiste en que aplicó este método a esta. ¿Como lo aplica?

Cuando un científico naturalista quiere explicar un hecho físico cualquiera, investiga las condiciones bajo las cuales tuvo lugar el fenómeno, casi el mismo procedimiento emplea Kant con la aparición de la ciencia, pues se pregunta:

¿Cuáles son las condiciones bajo las cuales tiene lugar el hecho del conocimiento humano? 
Kant procede a investigar las facultades del conocimiento, como las condiciones necesarias que preceden al hecho del conocimiento. Hasta entonces la mayor parte de las doctrinas filosóficas no habían negado los conocimientos humanos existentes, solo habían dejado indeciso su valor; después de este autor la filosofía debe obrar con mas cautela y no tomar nada por verdades indubitables. Su relación, pues, con los conocimientos existentes es escéptica; con la facultad de conocer critica, es decir, investiga, examina y analiza.

La filosofía prekantiana, sin pensar realmente en las condiciones del conocimiento, juzga sin recelo alguno la existencia de Dios, del mundo y de todas las cosas posibles; por esto era dogmática. En oposición a esta filosofía Kant plantea la filosofía crítica, pues aquella supone ya lo que debía haber investigado: la posibilidad del conocimiento.

La filosofía dogmática era metafísica, en sus vertientes racionalista o medieval, o experiencial, en el caso del empirismo ingles. Kant toma la metafísica y la experiencia como sus objetos de investigación por tanto la filosofía crítica no entra en oposición con la filosofía dogmática sino que es su objeto.

Existe una comparación excelente entre estas dos filosofías: la imagen de un ojo humano que contempla desde cierto punto de vista un campo dado: el ojo ve la imagen, los diversos objetos, que se reflejan en su retina; pero no se ve así mismo, ni su punto de vista, ni su ángulo visual, de este modo está la filosofía dogmática con las cosas. Si se tiene luego la imagen de otro ojo colocado en otro punto de vista, bajo tales condiciones que puede ver el otro ojo, puede observar y determinar el lugar en que se encuentra y su ángulo visual. Esta es la relación de la filosofía critica con la dogmática esta colocada en un lugar que supera a esta; la comprende desde su punto de vista, mientras que la dogmática esta de tal manera situada que no puede verse a si misma ni a la critica.

El filósofo dogmático es el ojo, cuyo objeto son las cosas. El filosofo critico es el óptico, cuyo objeto es el ojo, las imágenes de las cosas en el ojo, en una palabra, la vista misma. Esta analogía es imperfecta, como todas, solo trata de hacer visible la relación que existe entre ambas filosofías.

\section{LA ORIGINALIDAD DE KANT}

Es evidente que las explicaciones sobre el conocimiento humano, la investigación de nuestra capacidad de conocer, no son temas únicamente estudiados por Kant pues los filósofos antiguos ya trataban también esas cuestiones y en los inicios de la modernidad fueron el centro de muchas disertaciones.

Descartes escribió sobre los principios del conocimiento humano. Spinoza sobre la perfección del entendimiento. Malebranche sobre el conocimiento de la verdad. Locke hizo su ensayo sobre el entendimiento humano. Leibniz los nuevos ensayos sobre el entendimiento. Wolf sobre las facultades del mismo. Berkeley sobre los principios del entendimiento. Por ultimo Hume otro ensayo sobre el entendimiento.

Lo anterior permite afirmar que la teoría del conocimiento tiene un lugar indiscutible y notable en la filosofía de la modernidad y que todos esos filósofos han querido dar una explicación del conocimiento, también Kant 
trató el tema pero se apartó del camino de sus antecesores.

Ciertamente los filósofos anteriores a el, quisieron explicar el hecho del conocimiento, pero lo que creyeron haber encontrado como sus principios fundamentales fueron, si bien se analiza, verdaderos hechos de conocimiento. Los empiristas consideraban el conocimiento igual a la experiencia; hacían proceder la experiencia de las impresiones sensibles que se repetían y enlazaban por repeticiones. Sin embargo, este enlace de impresiones no fue de manera alguna explicado y solo fue admitido como un procedimiento natural, como hecho dado, evidente. Pero precisamente en este hecho consiste la experiencia. Y este hecho es precisamente el problema que se trataba de resolver.

Los metafísicos fundamentalmente y también los cartesianos, consideraban el conocimiento igual al pensamiento racional, y los explicaban por medio de las ideas innatas, de las que hacían principios que tenían por axiomas fundamentales de todo conocimiento. Pero les objeta Kant, los principios no son las condiciones del conocimiento, sino, a su vez, conocimientos efectivos.

Kant, concluye, que las suposiciones del las dos tendencias nada explican porque no son condiciones del conocimiento sino hechos del conocimiento y descubre que el hecho del conocimiento solo puede ser explicado por las condiciones que lo preceden, y estas condiciones eran las condiciones de la naturaleza humana.
Es precisamente en este punto donde interviene el importante giro que llama Kant revolución copernicana. En lugar de buscar fuera de nosotros la justificación de los juicios científicos, (búsqueda inútil porque la crítica de Hume plantea que la experiencia no puede ni podrá darnos algo universal y necesario), Kant propone buscarla en nuestro mismo proceso cognoscitivo.

La analogía con la revolución copernicana es evidente por dos razones:

1. En cuanto al planteamiento utilizado por Copérnico y Galileo para unir teoría y experiencia.

2. En cuanto Copérnico había propuesto buscar la causa del movimiento aparente de los cielos no en el cielo mismo sino en la tierra, de esta manera propone Kant buscar la base de los juicios universales $y$ necesarios no en la experiencia sino solo en nosotros.

Entonces, ¿Qué es el proceso cognoscitivo en el que tenemos que buscar el fundamento de las proposiciones científicas? ¿Cuál es la parte de ese proceso que corresponde a la actividad del sujeto? La respuesta de Kant es de máxima importancia "conocer» no significa un puro y simple recibir datos, sino que significa elaborarlos, sintetizarlos según formas a priori (categorías), propias de cada sujeto pensante. Toda nuestra experiencia, todo el mundo de la naturaleza es fruto de la síntesis de los datos operada por la actividad formadora o trascendental.

Es preciso aclarar la diferencia entre el apriori de Kant y las ideas innatas de la filosofía anterior, inclusive de la de Descartes. Estas son ideas que la mente descubre en si, 
perfectamente completas en forma $y$ contenido, y por lo tanto constituyen objeto de verdadero conocimiento. Las categorías apriori en Kant, en cambio son la forma y como tal no pueden constituir un objeto de conocimiento: son un instrumento indispensable para conocer la experiencia, en la medida que sintetizan los datos.

Toda la experiencia humana en el mundo es fruto de la síntesis de los datos y la actividad formadora o trascendental (las categorías apriori). La actividad trascendental organiza los datos empíricos según esas formas a priori, comunes, para Kant a todos los sujetos pensantes.

La determinación de las categorías a priori es una de las partes mas complicadas y artificiosas de Kant, y no se examinará en este escrito. Solo basta decir que las categorías mas importantes son la de substancialidad y causalidad que constituyen el fundamento ultimo último de la física pura o sea de la física como ciencia racional. Toda categoría esta preparada por un particular esquema y de valerse de el: por ejemplo, la causalidad se vale del esquema de la sucesión (la causa precede al efecto), la substancialidad se vale del esquema de la permanencia y así con todas las demás categorías. El resultado que se consigue, según Kant, es un una continuidad sin fracturas entre intelecto y sensibilidad.

Kant, plantea en la Critica de la Razón Pura que las categorías apriori del entendimiento constituyen el fundamento ultimo de las leyes de la naturaleza, sin embargo se encuentra frente a un problema aún mas difícil: el de justificar porque se habla del mundo fenoménico como de un único orden, como si estuviera basado en una realidad externa, reflejada de la misma manera por cada uno de los sujetos.

La respuesta a este problema la constituye la teoría de la «apercepción trascendental». Con ella Kant presenta las 12 categorías como otras tantas funciones, a través de las cuales se explica el pensamiento subjetivo. Este pensamiento es la forma suprema de la actividad sintetizadora, o sea, la forma que imprime unidad y coherencia a toda experiencia. Este pensar del sujeto es la garantía de un orden, no solo entre lo que el yo individual piensa ahora y lo que pasó antes, sino tambien entre lo que piensa un yo y lo que piensan los otros yo.

Mientras que las filosofías anteriores habían buscado la anterior garantía en un ser que trascendiera la naturaleza, (en un Dios capaz de determinar desde la eternidad la perfecta correspondencia entre los contenidos particulares del pensamiento y los objetos de la experiencia), ahora esta se buscaba en el yo. Pero no en el yo como sustancia, o sea, como entidad en sí diferente del acto de pensar, sino en el yo como función, o sea un yo como actividad sintetizadora de los datos de la experiencia.

\section{NOTAS}

(1) KANT, Manuel. Critica de la razon pura. Orbis, 1985, Pág. 130. 


$$
\infty
$$

